\title{
Research on competitiveness evaluation of logistics enterprises in China
}

\author{
Zhang Zongying, Liu Jie \\ Female,Shandong Foreign Trade Vocational College,Post Code 266100 \\ Male,Shandong Foreign Trade Vocational College,a PhD candidate at Wuhan University, Post \\ Code 266100
}

Key words: logistics enterprise; competitiveness; empirical; analysis

\begin{abstract}
With the rapid development of social economy, the economic interaction between regions and regions is more and more frequent, so in this process, it is necessary to use logistics to achieve the effective transport and sales of goods. In the development of modern logistics, whether the management experience is rich, the management technology is advanced, and whether the organization planning is reasonable, is the key factor affecting the market competitiveness of logistics enterprises. Based on this, this paper conducted a comprehensive analysis for the current competitiveness of logistics enterprises, with a view to the long-term stable development of logistics enterprises to provide help.
\end{abstract}

\section{Introduction}

At present, the logistics enterprises in our country are developing rapidly, and meet the needs of people's work and life. However, in the increasingly fierce logistics market development, enterprises need timely according to the needs of users, the actual situation of market competition, constantly improve their comprehensive level, so as to gain a firm foothold in the fierce market competition.

\section{The construction analysis of the evaluation model of logistics enterprise competitiveness}

The logistics enterprises own the development strength, and the operation ability, is the enterprise can in the market, continuously obtains the development reason. At the same time, with the help of the competitiveness of logistics enterprises, we can also effectively reflect the competitiveness of our entire logistics enterprises. Therefore, for the competitiveness of our logistics enterprises, we can use the evaluation model of competitiveness, to conduct a comprehensive grasp and evaluation, and then find a new way to promote the development of logistics enterprises in our country. The competitiveness of China's logistics enterprises, mainly from the enterprise market, management, technology competitiveness, these three aspects of research.[1]

At present, the evaluation model of competitiveness, using the fuzzy comprehensive evaluation method, this method can be used to evaluate the fuzzy factors in these three aspects, effective solution, so the evaluation results are more accurate. When the evaluation model is established, the comprehensive competitiveness factors of the enterprise need to be identified. The analytic hierarchy process can be used to calculate the weight of its specific competitiveness. Logistics enterprises in the process of development will produce more indicators, after the average division obtain the index weight value. Among them, the index is divided according to the size of impact, and to do a good mark. If A1 is compared to A2, there is little difference in the importance of them, You can use 1 to make a level of markup. If the former is more important between the two indicators, then you can use 3 to mark it. If the former than the latter important degree is more intense, you can use 5 to mark. For some of these intermediate values, you can use 2, 4 to mark. After marking the indicators in their development according to the degree of importance, can be arranged into a matrix, to obtain the vector values of its various indicators. According to the vector value and matrix obtained, a new vector value is obtained. After that, add all of the vector values obtained, compared with the number of components, according to the resulting divisor, the $\lambda$ 
maximum value can be obtained. Finally, in this system, according to the obtained approximation, the matrix can be determined, and the consistency of the matrix can be analyzed. The value of $\lambda$ is compared with the order value of the matrix, the certainty of the consistency of the matrix can be determined accurately. If the consistency of its matrix appears a certain error condition in the process of judgment, it can be expressed through formula: $\frac{\lambda_{\max }-n}{n-1}$, to express. According to the index data obtained by this formula, the error value of the consistency can be judged effectively. The number of values obtained can be expressed using $\mathrm{c} 1$. This value is in a small case, it can show the consistency of the matrix, very large [ 2 ].

After judging the competitiveness of the enterprise, we need to judge the fuzzy index in its development. This fuzzy factor, using the fuzzy statistical method to evaluate. Select the logistics company which needs to evaluate the competitiveness, use competitiveness as the key words of index retrieval, then the relevant factors related to the enterprise development competitiveness index are gathered. Then, we can use the questionnaire to study and analyze the strength of the index.Using competitiveness as the key words of enterprise competitiveness evaluation, help researchers carry out comprehensive identification and judgment of some more fuzzy factors which beyond the competitive factors of qualitative, in the enterprise development process. It makes a comprehensive analysis of the various factors that affect the competitiveness of logistics enterprises, and then can provide effective evidence support for its judgment results. At present, the recognition of its competitiveness can be carried out from the content and characteristics of the competitiveness of the enterprise development, and comprehensive judgment of its existing factors [ 3 ].

After the establishment of the evaluation model, we know that the market competitiveness of the logistics enterprise competitiveness, can use A1 to express, the other technology, management competitiveness, can use A2, A3, in their respective competitiveness, under the control of specific competitiveness content. For example, in the market competitiveness of the enterprise, it includes the core business capability and product capability, which can be represented by X11 and X12. In its technology and management competitiveness, according to its core technology application ability, leading ability, and human resource management ability, enterprise culture and so on, can be represented by X21, X22; X31、X32. According to the above expression method, the specific evaluation model can be established. The set of factors in the model can be represented by A. The market, technology and management competitiveness can represented by A1, A2, A3, and their various forms of expression can be expressed as: $A 1=(X 11 ; X 12) 、 A 2=(X 21 ; X 22)$ 、 $A 3=(X 31 ; X 32)$. Then, in the establishment of the competitiveness evaluation model, using $\mathrm{V}$ as the evaluation result of the flat language set, to express, then its specific $\mathrm{V}$ value corresponding to three indicators. That is, strong, stronger, general, weak, to carry out the effective expression of enterprise competitiveness. In the application of the model, it also needs to make a weight analysis of its specific three competitiveness indicators, and get the $\mathrm{N}$ value of the weight. Finally, have a comprehensive evaluation of the results, get the membership degree, to judge competitiveness.

\section{Empirical analysis}

Select a logistics enterprise, use the model to study the competitiveness of the object. Combined with the research data, the specific competitiveness of the situation, a comprehensive analysis and research. Firstly, the competitiveness factors of the enterprise are identified, and then calculate the index weight of each factor. According to its recognition results, the ranking vector of the market competitiveness is 0.5 ; The ranking vectors of its technology and management competitiveness are: $0.25,0.5$. After the consistency of the matrix of the results, in the case where the consistency is more ideal, the specific weight values of the three indexes are: $0.3,0.3,0.4$. The three main competitiveness factors of the enterprise, the specific impact factors, calculate the weight, the market competitiveness under the weight of the content is: $0.5 ; 0.5$. The weight value under the technology and management factors can be recorded as: $0.3,0.2 ; 0.4 ; 0.3$. In addition, it also needs 
to identify and analyze the fuzzy factors in the enterprise development. The concrete can be evaluated from the three aspects: advancement, ductility, historical dependence and value. After calculation, the four factors can be calculated, and their weight values are: 0.3, 0.2, 0.3, 0.20. By multiplying it by 100, you can get a specific score for each part, that is, 30, 20, 30, 20. In addition, when using the model to determine the competitiveness of the enterprise, it also needs to conduct a survey of the management personnel of the logistics enterprises, issue a questionnaire, investigate the strength of competitiveness. According to the effective questionnaire, it can provide some reference data to the results of its strong and weak judgment. Then, according to the proportion of the score, according to the $\mathrm{v}$ value corresponding to the strength of the competitiveness to make intuitive judgment of the specific competitiveness of the situation. According to the principle of the maximum membership degree, the competitiveness of the enterprise can be analyzed, its specific value is: $0.15,0.50,0.30,0.09$. The enterprise as the research object in its competitiveness is strong.

\section{Suggestions or countermeasures to improve the competitiveness of logistics enterprises}

4.1 Continuously strengthen the application of information technology and promote the construction of its service network. In the development of modern logistics enterprises, in order to achieve effective communication between regional economic exchanges, it is necessary to strengthen the application of information technology. In order to achieve the effective integration of the regional logistics development business, better in-depth to the customer's production activities, and establish a logistics development of the national network system. At the same time, in the development of enterprises, according to the formation of this logistics network, establish the logistics operation network constantly in all regions of the country, better adapt to the modern economic development of the various areas of logistics business needs. Through the logistics network, we can achieve the effective transfer and management of the development information of the whole logistics enterprise, and avoid some unnecessary process in its operation, so as to continuously improve its market competitiveness and expand the market share [4].

4.2 Promoting enterprise's intensive management. In the process of the development of logistics enterprises, in view of their development scale, geographical and business constraints, we need to conduct detailed research on the current development market, so as to fully understand the needs of market development. It can provide a more comprehensive service for the society and users according to the survey data, and establish the concept of the national logistics development, by the large scale logistics enterprises to integrate the existing logistics enterprises, to achieve the strong cooperation between enterprises, and finally achieve the comprehensive development of the trans-regional logistics enterprises, and ultimately achieve the effective allocation of logistics information resources, achieve intensive management.

4.3 Improve the service quality of logistics enterprises. In the development of logistics enterprises, to constantly improve their market share, we need to constantly improve the quality of their services, combined with the needs of users, timely improvement. It can according to the needs of different customer groups, establish a detailed service content, in order to better meet different people, for the need of logistics transportation services. In addition, logistics enterprises can also provide a certain value-added services for users in the process of development, for the development of enterprises, to cultivate a group of potential customer groups and ultimately promote the sustainable development of enterprises.

\section{Concluding remarks}

In the current development of logistics enterprises, in order to effectively promote enterprises to obtain the maximum market share, the competitiveness needs to be analyzed accurately. Then according to the analysis results, we can understand the problems and shortcomings of the enterprise itself, and then in the follow-up development process, timely take corresponding 
measures to improve its problems, and ultimately promote the continuous improvement of its competitiveness.

\section{References:}

[1] Yuan Yali. Research on competitive evaluation of logistics enterprises in China [D]. Changsha University Science\&technology, 2009.

[2] Zhao Yan. Research on the evaluation and countermeasures of the competitiveness of logistics enterprises in China [D]. Northeast Forestry University, 2005.

[3] Guan Qingjun. Research on the evaluation of the competitiveness of the third - party logistics enterprises in China [D]. Jiangxi University of Science and Technology, 2012.

[4] Wang Kun. Analysis and evaluation of the competitiveness of logistics enterprises in China [D]. Jiangxi University of Finance and Economics, 2006. 